\title{
EFFECTS OF PROPOLIS EXTRACT AND PROPOLIS CANDIES AGAINST CANDIDA ALBICANS ATCC 10231 GROWTH
}

\section{WIDA PRISKA MELINDA, NURTAMI SOEDARSONO, RATNA FARIDA*}

\author{
Department of Oral Biology, Faculty of Dentistry, Universitas Indonesia, Jakarta, Indonesia. Email: friedakuayu@yahoo.co.id
}

Received: 20 April 2017, Revised and Accepted: 13 July 2017

ABSTRACT

Objectives: This research was aimed at analyzing the effect of propolis extract and candies on Candida albicans growth.

Methods: After C. albicans was exposed to propolis extract and candies, the minimum inhibitory concentration (MIC) and minimum bactericidal concentration (MBC) were determined with spectrophotometry, and post-exposure colonies of $C$. albicans were counted.

Results: The MIC of propolis extract against $C$. albicans was determined to be $10 \%$ and MBC to be $15 \%$. Furthermore, $C$. albicans colonies were decreased after propolis extract and candies exposure.

Conclusions: Propolis extract and candies were effective to inhibit $C$. albicans growth.

Keywords: Candida albicans, Candy, Extract, Propolis.

(C) 2017 The Authors. Published by Innovare Academic Sciences PvtLtd. This is an open accessarticle under the CC BY license (http://creativecommons. org/licenses/by/4. 0/) DOI: http://dx.doi.org/10.22159/ajpcr.2017.v10s5.23084

\section{INTRODUCTION}

Candidiasis is an oral soft tissue disease. Candidiasis is an infection which happens because of a fungal growth called Candida. The Candida species is mostly found in the oral cavity, and the one that causes candidiasis is Candida albicans [1]. Propolis is known as an antifungal agent. The previous study has found that propolis has the same effectivity as nystatin antifungal [2]. Propolis is a natural ingredient produced by bees. Propolis is composed of 55\% resin and balm such as flavonoid, fenolat acid, and caffeic acid phenylethyl ester; $30 \%$ beeswax; $10 \%$ essential oil; and 5\% pollen [3]. One active biochemical substance in propolis is flavonoid, which acts as an antibacterial, antifungal, antiviral, and anti-inflammation agent. There is another bee product besides propolis that contains flavonoid: Honey. However, compared to honey, propolis has the highest antimicrobial activity [4]

Many studies about propolis usage in dentistry have been done, such as the usage of propolis as the base of mouthwash, base of toothpaste, and as a wound healer. Currently, a candy product that contains propolis is being developed and is differentiated by the type of the sweetener used, which is sucrose or palm sugar. Palm sugar is used as a substitute because it contains a lower level of sucrose. Some in vitro studies found that propolis can inhibit $C$. albicans growth $[1,2,4]$. However, there is no research about the effect of propolis and propolis candies against C. albicans growth. This research aims to test the propolis extract and candies made by Universitas Indonesia, which contain honey propolis with sucrose sweetener and palm sugar sweetener, and their effect against $C$. albicans growth.

\section{METHODS}

This research was an in vitro laboratory experiment. The samples used were $C$. albicans ATCC 10231. The $C$. albicans hatching media used were sterilized using Sabouraud Dextrose Agar (SDA) and Sabouraud Dextrose Broth (SDB). First, propolis extract was diluted using glycerin to obtain propolis extract with different concentrations. The propolis extract concentrations that were used in this research were $0.5 \%, 1 \%$, $5 \%, 10 \%, 15 \%$, and $20 \%$. Then, tubes containing propolis extract in different concentrations were saved in a refrigerator in $4^{\circ} \mathrm{C}$ until the time we wished to use them. The propolis candies used were propolis candies containing artificial sucrose made by Universitas Indonesia, which contain $5 \%$ propolis extract, $3 \%$ honey, $41 \%$ glucose syrup, $41 \%$ sugar, and $10 \%$ water; propolis candies containing artificial palm sugar made by Universitas Indonesia, which contain 5\% propolis extract, $41 \%$ glucose syrup, $41 \%$ palm sugar, and $10 \%$ water; and X propolis candies, which are throat lozenges available in the market and contain propolis powder, lactitol, polydextrose, vanilla powder, licorice, menthol crystal, acesulfame-K, soy lecithin, and a flavoring agent. Each candy was crushed using a mortar. After they become powder, they were measured using an OHOUS scale to get $4 \mathrm{~g}$ of candies. Then, they were filtered using a syringe filter (sartorius $0.22 \mu \mathrm{L}$ ) to get sterilized candy liquid.

The minimum inhibitory concentration (MIC) was determined using spectrophotometry. A suspension of $100 \mu \mathrm{l}$ of $C$. albicans at a $10^{-4}$ concentration was inserted into a 96 -well plate. Then, $100 \mu \mathrm{l}$ of propolis extract at different concentrations were added. Blank samples, which are samples that contained only propolis extract in each concentration and SDB medium without fungi, were prepared. The plates were anaerobically incubated at $37^{\circ} \mathrm{C}$ for $48 \mathrm{hrs}$. After incubation was finished, the optical density (OD) score was read using a microplate reader with $450 \mathrm{~nm}$ wavelength. The inhibition score was stated in percentages. From the 96-well plates containing $C$. albicans suspensions that had been exposed with propolis extract, $10 \mu \mathrm{l}$ was taken and inserted in the SDA hatching medium. Then, they were incubated at $37^{\circ} \mathrm{C}$ for $48 \mathrm{hrs}$. After incubation finished, fungal colonies were counted. The MIC was counted based on the number of bacteria colonies in SDA medium. About $10 \mu \mathrm{l}$ of $C$. albicans that had been exposed to the propolis candies were taken and inserted into the SDA medium. The $C$. albicans had been exposed to the honey propolis liquid candy containing sucrose, the honey propolis candy containing palm sugar, and the $\mathrm{X}$ propolis candy. Then, they were incubated in $37^{\circ} \mathrm{C}$ for $48 \mathrm{hrs}$. After incubation finished, fungal colonies were counted.

\section{RESULTS}

In this research, $0.5 \%, 1 \%, 5 \%, 10 \%, 15 \%$, and $20 \%$ propolis extract concentrations were used. The results showed that the inhibition score against $C$. albicans ATCC 10231 increased as the concentration of propolis extract used increased (Table 1 ) 
From Table 1, it can be seen that the 15\% concentration propolis extract had the highest mean inhibition score, which was $143.33 \%$ $( \pm 8.97)$. ANOVA tests were done to obtain the significance score of the propolis extract in different concentrations compared with the controlled inhibition score without propolis extract, and $\mathrm{p}<0.025$ was acquired in every concentration. Then, the MIC score was determined if the inhibition score reached $\geq 90 \%$ and looked visually clear. Based on this research, the $10 \%$ concentration propolis extract with a mean inhibition score of $102 \%( \pm 4.58)$ was determined to be the propolis extract MIC. Fungal colonies of $C$. albicans ATCC 10231 that had been exposed to the different concentrations of propolis extract $(0.5 \%, 1 \%$, $5 \%, 10 \%, 15 \%$, and $20 \%$ ) were then counted. The number of fungal colonies can be seen in Table 2 .

From Table 2, it can be seen that there were a decreasing number of colonies after exposure to the different concentrations of propolis extract compared with the controlled group without the propolis extract. The $0.5 \%$ concentration of propolis extract had the highest mean number of colonies, which was $110 \times 10^{4}( \pm 13.55)$. The $15 \%$ concentration of propolis extract had the lowest number of colonies, which was 0 . ANOVA tests were done to compare each propolis extract concentration to the number of $C$. albicans colonies that grow. They showed a statistically significant difference $(\mathrm{p}<0.025)$. The minimum bactericidal concentration (MBC) score could be determined if there were no fungal colonies growing in certain concentration. Based on the earlier findings, we can see that the $15 \%$ concentration was the MBC score. Table 3 shows the number of colonies after $C$. albicans ATCC 10231 was exposed to propolis candy containing palm sugar, honey propolis candy containing sucrose, and X propolis candy.

From Table 3, it can be seen that the number of $C$. albicans colonies before exposure to the candies was $1850 \times 10^{4}$. After being exposed to the honey propolis extract containing sucrose, the number of growing C. albicans colonies were $1500 \times 10^{4}$. After being exposed to the $\mathrm{X}$ propolis candy, the number of $C$. albicans colonies were $1400 \times 10^{4}$. Finally, after being exposed to the honey propolis candies containing

Table 1: Propolis extract inhibition score against C. albicans ATCC 10231

\begin{tabular}{|c|c|c|c|c|c|}
\hline $\begin{array}{l}\text { Controlled inhibition score } \\
\text { without propolis extract }(\%)\end{array}$ & $\begin{array}{l}\text { Propolis extract } \\
\text { concentration (\%) }\end{array}$ & Sample & $\begin{array}{l}\text { Inhibition } \\
\text { score }(\%)\end{array}$ & $\begin{array}{l}\text { Inhibition score } \\
\text { mean }(\%) \pm S D\end{array}$ & $\begin{array}{l}\text { p-value against controlled } \\
\text { sample without propolis extract }\end{array}$ \\
\hline \multirow[t]{3}{*}{0} & 0.5 & 1 & 28 & $29 \pm 2.64$ & $0.000^{*}$ \\
\hline & & 2 & 27 & & \\
\hline & & 3 & 32 & & \\
\hline \multirow[t]{3}{*}{0} & 1 & 1 & 62 & $68.66 \pm 9.06$ & $0.000^{*}$ \\
\hline & & 2 & 65 & & \\
\hline & & 3 & 78.98 & & \\
\hline \multirow[t]{3}{*}{0} & 5 & 1 & 89 & $89.66 \pm 1.89$ & $0.000 *$ \\
\hline & & 2 & 88 & & \\
\hline & & 3 & 91.66 & & \\
\hline \multirow[t]{3}{*}{0} & 10 & 1 & 107 & $102 \pm 4.58$ & $0.000^{*}$ \\
\hline & & 2 & 98 & & \\
\hline & & 3 & 101 & & \\
\hline \multirow[t]{2}{*}{0} & 15 & 1 & 133.56 & $143.33 \pm 8.97$ & $0.000 *$ \\
\hline & & 2 & 145.23 & & \\
\hline \multirow[t]{3}{*}{0} & 20 & 1 & 129.31 & $130.3 \pm 1.23$ & $0.000 *$ \\
\hline & & 2 & 131.70 & & \\
\hline & & 3 & 129.98 & & \\
\hline
\end{tabular}

C. albicans: Candida albicans. *Significant value $\mathrm{p}<0.025$

Table 2: Number of $C$. albicans ATCC 10231 colonies after exposure to propolis extract in different concentrations

\begin{tabular}{|c|c|c|c|c|c|}
\hline $\begin{array}{l}\text { Controlled } C \text {. albicans } \\
\text { colonies count }\left(10^{4} \mathrm{cell} / \mathrm{ml}\right) \\
\text { without propolis extract }\end{array}$ & $\begin{array}{l}\text { Propolis extract } \\
\text { concentration (\%) }\end{array}$ & Sample & $\begin{array}{l}\text { Candida albicans } \\
\text { colonies }\left(10^{4} \text { cell } / \mathrm{ml}\right)\end{array}$ & $\begin{array}{l}\text { Mean Candida albicans } \\
\text { colonies }\left(10^{4} \text { cell } / \mathrm{ml}\right) \pm S D\end{array}$ & $\begin{array}{l}\text { p value against } \\
\text { controlled group } \\
\text { without propolis } \\
\text { extract* }\end{array}$ \\
\hline \multirow[t]{17}{*}{1460} & 0.5 & 1 & 110 & $110 \pm 13.55$ & 0.1 \\
\hline & & 2 & 97 & & \\
\hline & & 3 & 124 & & \\
\hline & 1 & 1 & 86 & $85 \pm 2.78$ & 0.080 \\
\hline & & 2 & 92 & & \\
\hline & & 3 & 78 & & \\
\hline & 5 & 1 & 56 & $50 \pm 3.92$ & 0.070 \\
\hline & & 2 & 44 & & \\
\hline & & 3 & 49 & & \\
\hline & 10 & 1 & 31 & $26 \pm 4.15$ & 0.050 \\
\hline & & 2 & 22 & & \\
\hline & & 3 & 26 & & \\
\hline & & 2 & 0 & & \\
\hline & & 3 & 0 & & \\
\hline & 20 & 1 & 0 & 0 & 0.000 \\
\hline & & 2 & 0 & & \\
\hline & & 3 & 0 & & \\
\hline
\end{tabular}

C. albicans: Candida albicans. *Significant value $\mathrm{p}<0.025$ 
Table 3: Number of C. albicans ATCC 10231 colonies after exposure to different propolis candies

\begin{tabular}{|c|c|c|c|c|c|}
\hline $\begin{array}{l}\text { Controlled } \text { C. albicans } \\
\text { colonies count }\left(10^{4} \text { cell } / \mathrm{ml}\right) \\
\text { without propolis candies }\end{array}$ & Treatment types & Sample & $\begin{array}{l}\text { C. albicans colonies } \\
\text { amount }\left(10^{4} \text { cell } / \mathrm{ml}\right)\end{array}$ & $\begin{array}{l}\text { C. albicans colonies amount } \\
\text { mean }\left(10^{4} \text { cell } / \mathrm{ml}\right) \pm \mathrm{SD}\end{array}$ & $\begin{array}{l}\text { p-value against } \\
\text { controlled group } \\
\text { without propolis } \\
\text { candies }\end{array}$ \\
\hline \multirow[t]{6}{*}{1850} & \multirow{4}{*}{$\begin{array}{l}\text { Sucrose propolis } \\
\text { candy } \\
\text { X propolis candy }\end{array}$} & 1 & 1480 & \multirow[t]{2}{*}{$1500 \pm 3.53$} & \multirow[t]{2}{*}{0.087} \\
\hline & & 2 & 1530 & & \\
\hline & & 1 & 1610 & \multirow[t]{2}{*}{$1400 \pm 29.69$} & \multirow[t]{2}{*}{0.076} \\
\hline & & 2 & 1190 & & \\
\hline & \multirow{2}{*}{$\begin{array}{l}\text { Palm sugar propolis } \\
\text { candy }\end{array}$} & 1 & 1270 & \multirow[t]{2}{*}{$1300 \pm 6.36$} & \multirow[t]{2}{*}{0.091} \\
\hline & & 2 & 1360 & & \\
\hline
\end{tabular}

C. albicans: Candida albicans

palm sugar, the number of $C$. albicans colonies were $1300 \times 10^{4}$. Based on the findings in Table 3, there was a decreasing number of $C$. albicans colonies after exposure to the candies, but statistical analysis showed that there was no statistically significant difference ( $p>0.025)$ between the effects of the different propolis candies on the number of $C$. albicans ATC10231 colonies.

\section{DISCUSSION}

In this research, the MIC score for propolis extract against $C$. albicans was the $10 \%$ concentration. The minimum killing concentration score attained was the $15 \%$ concentration. However, in the $20 \%$ concentration, there was a decrease in the inhibition score compared with the $15 \%$ concentration. In the propolis extract MIC test against C. albicans, there was fluctuation in the inhibitions scores. This was because the extract consistency in the $20 \%$ concentration was higher than that of the $15 \%$ concentration, which affected the OD score when read using a microplate reader. There was a decrease in the number of C. albicans ATCC 10231 colonies as the propolis extract concentration increased. This finding parallels research done by Al-Daamy (2015), which tested the effectivity of many concentrations of propolis against Candida sp. found that there was a significant decrease in the number of colonies as propolis extract concentration increased and found that C. albicans is the most reactive fungi to propolis [5].

This current research found that there was decreasing number of growing colonies after exposure to propolis candies. The propolis candy containing palm sugar was found to be more effective compared to $\mathrm{X}$ propolis candy, which contained dextrose sweetener, and honey propolis candy, which contained sucrose. This was proved by the lower number of colonies formed. This might be because palm sugar was less supportive of $C$. albicans ATCC 10231 growth compared to sucrose or dextrose. Glucose consumption is one of the predisposing factors for C. albicans growth. Results found in the previous studies showed that C. albicans adhesions increased after being given carbohydrates such as galactose, glucose, sucrose, fructose, maltose, and sorbitol [6-8].

Based on the results found in this research, it can be seen that propolis has an effect against C. albicans growth. Propolis can obstruct $C$. albicans growth because its active ingredient is flavonoid. This obstruction of growth probably happens because the flavonoid clusters contained in propolis are the same as antifungal agents such as nystatin. Flavonoid, as the active ingredient contained in propolis, is a phenol substance with an $-\mathrm{OH}$ cluster, which can be found in nystatin. Phenol substances can inhibit microbes' growth by their penetrative ability. Phenol can bond with the cellular membrane $C$. albicans by producing a hydrogen bond between its hydroxyl group and protein in the cellular membrane. This mechanism then creates an imbalance in the permeability of the cellular membrane. It causes cellular leakage and death. The propolis antifungal mechanism starts with contact between propolis and $C$. albicans. Propolis then inhibits the formation of germ tubes from $C$. albicans, preventing the transition of spores to mycelium. After C. albicans is incubated with propolis, vacuolization can be seen, and there are changes and disruptions from the outermost part of the spores, which then causes C. albicans intracellular material to come out. This disrupts cellular division and C. albicans replication, so $C$. albicans cannot make colonies $[9,10]$. This research found that $15 \%$ concentration propolis extract is effective in killing C. albicans ATCC 10231. Meanwhile, exposure to X propolis candy, propolis candy containing palm sugar, and propolis candy containing sucrose showed that propolis candy containing palm sugar was more effective in decreasing C. albicans ATCC 10231 growth. The hypothesis in this research was that propolis extract could inhibit C. albicans ATCC 10231 growth and that different types of propolis candies could decrease C. albicans ATCC 10231 colonies. Based on the results of this research, we can conclude that the hypothesis was accepted.

\section{CONCLUSION}

Propolis extracts were effective in inhibiting C. albicans ATCC 10231 growth, as shown with a MIC score of $10 \%$ and a MBC of $15 \%$. In addition, propolis-containing candies, such as propolis candy containing sucrose, propolis candy containing palm sugar, and X propolis candy, effectively decreased the growth of $C$. albicans AT 10231 colonies.

\section{REFERENCES}

1. Shokri H, Khosravi AR, Yalfani R. Antifungal efficacy of propolis against fluconazole-resistant Candida glabrata isolates obtained from women with recurrent vulvovaginal candidiasis cervical and vaginal cancer in a woman with chronic graft-versus-host disease. Int J Gynecol Obstet 2011;114(2):158-9.

2. Santos VR, Pimenta FJ, Aguiar MC, do Carmo MA, Naves MD, Mesquita RA. Oral candidiasis treatment with Brazilian ethanol propolis extract. Phytother Res 2005;19(7):652-4.

3. Shruthi E, Suma B. Health from the hive: Potential uses of propolis in general health. Int J Clin Med 2012;3(3):159-6262.

4. Kacaniova M, Melich M, Knazovicka V, Felsociova S, Sudzinova J. The antimicrobial activity of honey and propolis against yeasts Candida species activitatea antimicrobian. J Pharmacol Sci 2009;42(2):167-3.

5. Al Daamy AH, Ameer H, Zuhaer H. Antifungal activity of propolis against dermatophytes and Candida albicans isolated from human mouth. J Contemp Med Sci 2015;1(3):4-8.

6. Abu-Elteen KH. The influence of dietary carbohydrates on in vitro adherence of four Candida species to human buccal epithelial cells. Microb Ecol Health Dis 2005;17(3):156-2.

7. Santana IL, Gonçalves LM, de Vasconcellos AA, da Silva WJ, Cury JA, Del Bel Cury AA. Dietary carbohydrates modulate Candida albicans biofilm development on the denture surface. PLoS One 2013;8(5):e64645.

8. Jin Y, Samaranayake LP, Samaranayake Y, Yip HK. Biofilm formation of Candida albicans is variably affected by saliva and dietary sugars. Arch Oral Biol 2004;49(10):789-98.

9. Arslan S, Silici S, Percin D, Koc AN, Er O. Antimicrobial activity of poplar propolis on mutans streptococci and caries development in rats. Turk J Biol 2012;36:65-73.

10. Senka B, Pašić Š, Behija D, Agnesa Č. Antifungal activity of propolis originated from Bosnia and herzegovina antifugalno djelovanje bosansko-hercegovačkog. Veterinaria 2011;60(3-4):18793. 